\title{
MISTURA DE QUATRO ONDAS (FWM): EFEITO DA ALOCAÇÃO DE CANAIS EM SISTEMAS OOPTICOS MULTICANAL (WDM) COM LARGỦRA DE BANDA CONSTANTE E GRADES ULTRAFINAS
}

\author{
José Rodolfo Souzal \\ Paula Brandão Harboe ${ }^{2}$
}

\begin{abstract}
Resumo: O presente trabalho investiga o efeito da alocação de canais nas penalidades impostas pelo mecanismo de mistura de quatro ondas (FWM - Four-Wave Mixing) em sistemas DWDM (Dense Wavelength Division Multiplexing) baseados em fibras monomodo de dispersão deslocada (G.653), mantendo constante a largura de banda do sistema. A potência de FWM, calculada sob a hipótese de bombeio sem depleção, é usada para determinar a taxa de erro de bits (BER), tomada como medida do desempenho dos sistemas. São considerados seis esquemas de alocação de canais: espaçamento uniforme (EU), duplo espaçamento uniforme (EU-EU), espaçamento não uniforme (ENU), espaçamento não uniforme repetido (ENUR), espaçamento não uniforme refletido (ENU-2) e espaçamento randômico (RAND), baseados nas grades de 100, 50, 25, 12,5 e 6,25 GHz. Os resultados, inéditos na literatura, investigam como, para uma dada BER, a potência total de sinal na entrada da fibra deve ser variada em função do posicionamento e número de canais, do comprimento da fibra e da taxa de transmissão e mostram que, de modo geral, a realocação dos canais na largura de banda do sistema reduz as penalidades impostas por FWM. Comparativamente, o esquema EU-EU, proposto pelos autores, revelou-se o mais eficiente, propiciando uma melhora significativa da BER, para uma dada potência de entrada, o que se traduz em uma relaxação da sensibilidade do receptor e/ou em um aumento do comprimento do enlace.
\end{abstract}

Palavras-Chave: Alocação de frequências, taxa de bits errados (BER), mistura de quatro ondas (FWM), sistemas WDM.

\begin{abstract}
This work investigates how the channel allocation - keeping the system bandwidth constant affects the penalties imposed by the four-wave mixing mechanism on DWDM systems based on monomode, dispersion-shifted optical fibers (G.653). The FWM power is calculated under the undepleted-pump hypothesis, and is used to evaluate the bit-error rate (BER), which is taken as a measure of the systems performance. Six channel allocation schemes (uniform spacing (EU), doubly-uniform spacing (EU-EU), non-uniform spacing (ENU), repeated non-uniform spacing (ENUR), reflected non-uniform spacing (ENU-2), and random spacing (RAND)) are considered, based on the 100, 50, 25, 12.5, and 6.25 GHz grid. Among the six schemes, ENU, ENUR, and RAND are adapted from others reported in the literature; EU-EU, and ENU-2 are proposed by the authors for the first time. The results, not reported in the literature yet, show how the input power per channel varies as a function of the spectral position, and number of channels, length of fiber, and transmission rate; the results indicate that the channel reallocation within the systems bandwidth effectively reduces the penalties imposed by FWM. The EU-EU scheme presented the greatest efficiency in FWM reduction, allowing for a significant improvement of the BER, which translates in a relaxation of the receiver sensitivity and/or an increase of the link length.
\end{abstract}

Keywords: Frequency allocation, bit-error rate (BER), four-wave mixing (FWM), WDM systems.

\footnotetext{
Departamento de Eletrônica e Telecomunicações, Universidade do Estado do Rio de Janeiro, jrsouza@uerj.br

2 Departamento de Engenharia de Telecomunicações, Universidade Federal Fluminense, paula@telecom.uff.br
} 


\section{INTRODUÇÃO}

O desenvolvimento de sistemas ópticos WDM (Wavelength Division Multiplexing) de alta capacidade requer o aumento da taxa de transmissão por comprimento de onda (de 2,5 para $10 \mathrm{e}$ $40 \mathrm{~Gb} / \mathrm{s}$ ) e/ou o aumento do número de comprimentos de onda, mantendo a granularidade da taxa de transmissão. A segunda abordagem utiliza espaçamentos entre canais cada vez menores, para maior exploração da limitada largura de banda dos amplificadores ópticos, e evita a eletrônica de alta velocidade ( $40 \mathrm{~Gb} / \mathrm{s})$, além de ser compatível com os equipamentos SONET/SDH (2,5 e 10 $\mathrm{Gb} / \mathrm{s}$ ) existentes.

Nos primeiros sistemas WDM, e em conformidade com a recomendação ITU-T G.692, os espaçamentos típicos eram de 100 e $50 \mathrm{GHz}$. Em 2002, com a publicação da recomendação G.694.1, as grades de 25 e 12,5 GHz também foram incorporadas. No entanto, estas grades sofrem de limitação no número de canais transmitidos, devido à dificuldade em gerenciar muitas fontes ópticas. Em um futuro próximo, sistemas DWDM com espaçamentos entre canais menores que $12,5 \mathrm{GHz}$ serão indispensáveis. A literatura recente (MIZUNO, 2004), (OHARA, 2005) mostra a condução de alguns experimentos com sistemas DWDM, assim como a gama de dispositivos que vêm sendo construídos para essas aplicações. Entretanto, até onde os autores têm conhecimento, as limitações fundamentais e penalidades impostas a esses sistemas com espaçamentos ultrafinos ainda carecem de investigação detalhada.

No cenário descrito, significativa interferência entre canais (crosstalk) pode ocorrer devido, principalmente, ao efeito não linear de mistura de quatro ondas (FWM), que é responsável pela geração de novas frequências ópticas. Em particular, nos sistemas que empregam fibra de dispersão deslocada (DSF), como os sistemas submarinos largamente instalados nos anos 90, o mecanismo de FWM é acentuado, devido à redução do descasamento de fase associado à baixa dispersão cromática da fibra na terceira janela de transmissão.

Ao longo dos anos, diferentes técnicas foram propostas e avaliadas, numérica e experimentalmente, visando a redução dos efeitos deletérios de FWM, incluindo: alocação espectral dos canais de forma que o espaçamento entre eles seja o maior possível; alocação espectral dos canais tão afastados quanto possível do comprimento de onda do zero de dispersão da fibra $\left(\lambda_{\mathrm{ZD}}\right)$; utilização de fibra de dispersão deslocada não-nula (NZDSF) e alocação espectral de canais utilizando espaçamento não uniforme entre os mesmos.

A técnica de alocação não uniforme de canais permite, de fato, uma redução nas penalidades impostas por FWM e tem sido tema de diversos trabalhos recentes SOUZA; HARBOE, 2003), (HARBOE; SILVA; SOUZA, 2008a2008c), (SILVA, 2008), (KOJIMA; NUMAI, 2006), (NAGATANI, 2008), (ONISHI; KOJIMA; NUMAI, 2007). Contudo, em todos estes trabalhos, nenhuma restrição é imposta à largura de banda total do sistema, que depende fortemente do esquema de alocação de canais adotado. Por exemplo, para o esquema baseado na régua ótima de Golomb (OGR - Optimum Golomb Ruler) (LAWSON, 2009), a largura de banda se torna tão grande que inviabiliza a adoção prática do referido esquema.

Este trabalho tem como principal objetivo investigar a influência do posicionamento espectral dos canais na geração de FWM, mas agora mantendo constante a largura de banda do sistema. Nesta análise, as grades DWDM - com espaçamentos $\Delta \mathrm{f}=100,50,25$ e $12,5 \mathrm{GHz}$ - definidas na Recomendação ITU-T G.694.1, e também a grade ultrafina de $\Delta f=6,25 \mathrm{GHz}$, são tomadas como base para um primeiro posicionamento de canais, de acordo com um esquema de espaçamento uniforme (EU). Para um sistema de $\mathrm{N}$ canais, a correspondente largura de banda é dada por: $\mathrm{B}_{\mathrm{EU}}$ $=(\mathrm{N}-1) \Delta \mathrm{f}$. Em seguida, esquemas de alocação não uniforme de canais são investigados, alguns deles já estudados na literatura, outros propostos neste trabalho. Em todos eles, a largura de banda $\mathrm{B}_{\mathrm{EU}}$ é mantida constante, o que exige um reposicionamento ou realocação dos canais na referida banda, em relação ao esquema EU.

Seis esquemas de alocação de canais são aqui considerados: espaçamento uniforme (EU), duplo espaçamento uniforme (EU-EU), espaçamento não uniforme (ENU), espaçamento não uniforme repetido (ENUR), espaçamento não uniforme refletido (ENU-2) e espaçamento randômico (RAND). Os esquemas ENU e ENUR são adaptados de outros já propostos na literatura (KOJIMA; NUMAI, 2006), (NAGATANI, 2008), (ONISHI; KOJIMA; NUMAI, 2007), 
tendo em vista os bons resultados relatados. Os esquemas ENU-2 e EU-EU, no melhor entendimento dos autores, não foram, ainda, tratados na literatura. $\mathrm{O}$ esquema de alocação com base na OGR não é considerado aqui porque, neste caso, o mínimo espaçamento entre canais é uma unidade da régua de Golomb, o que exigiria filtros ópticos de largura excessivamente estreita.

$\mathrm{O}$ trabalho enfatiza sistemas baseados em fibra monomodo de dispersão deslocada (DSF G.653), devido à extensa malha submarina instalada e ao fato de que esses sistemas são os mais afetados pelo fenômeno de FWM. O caso de sistemas que empregam as modernas fibras de dispersão deslocada não-nula (NZDSF - G.655) já está sob investigação, e será relatado posteriormente, em outra publicação. A fibra monomodo padrão (SMF - G.652) não é considerada, pois apresenta valores elevados do parâmetro de dispersão na faixa de comprimentos de onda de interesse (em torno de $1550 \mathrm{~nm}$ ) e, portanto, não propicia a geração de FWM.

$\mathrm{Na}$ análise de casos, são considerados sistemas de 24 e 48 canais e, principalmente, as grades ultrafinas de 25, 12,5 e 6,25 GHz. O desempenho dos sistemas é avaliado por meio da BER, tendo por base as potências de sinal, FWM e ruído medidas na largura de banda do filtro óptico de canal. Os resultados indicam que, de um modo geral, a alocação de canais segundo os esquemas explorados, mantendo constante a largura de banda do sistema, permite reduzir a geração de FWM em comparação com o esquema EU especificado na Recomendação G.694.1. O esquema EU-EU é o que apresenta o melhor desempenho: para uma BER $=10^{-12}$, permite aumentos superiores a $1,5 \mathrm{~dB}$ na potência de entrada por canal em um sistema de 24 canais. Isto pode representar uma relaxação da sensibilidade do receptor ou um aumento do comprimento do enlace.

O trabalho está organizado da seguinte forma. Inicialmente, na Seção 2, os principais conceitos associados ao mecanismo de FWM e aos esquemas de alocação de canais são destacados. As quantidades descasamento de fase, potência de FWM e taxa de bits errados de um sistema WDM são definidas. Esta formulação matemática é, então, usada para implementar um simulador WDM. Em seguida, na Seção 3, uma análise de casos é apresentada, e importantes resultados são discutidos. A Seção 4 apresenta as conclusóes do trabalho.

\section{FUNDAMENTOS DA ANÁLISE}

\subsection{MISTURA DE QUATRO ONDAS (FWM)}

A evolução da amplitude de um sinal de FWM ao longo de uma fibra óptica monomodo é descrita por (SOUZA; HARBOE, 2003), (HARBOE; SILVA; SOUZA, 2008a-2008c), (SILVA, 2008):

$$
\begin{aligned}
& \frac{\mathrm{dA}_{\mathrm{F}}}{\mathrm{dz}}+\frac{\alpha}{2} \mathrm{~A}_{\mathrm{F}}=\mathrm{i} \frac{\mathrm{n}_{2} \omega_{\mathrm{F}}}{\mathrm{c} \mathrm{A}_{\mathrm{eff}}} \mathrm{A}_{\mathrm{p}} \mathrm{A}_{\mathrm{q}} \mathrm{A}_{\mathrm{r}}^{*} \exp (.) \\
& \operatorname{com} \quad(.)=\mathrm{i}\left(\beta_{\mathrm{p}}+\beta_{\mathrm{q}}-\beta_{\mathrm{r}}-\beta_{\mathrm{F}}\right) \mathrm{z}
\end{aligned}
$$

$\mathrm{Na}$ equação (1), $\mathrm{A}_{\mathrm{F}}$ é a amplitude do sinal de FWM gerado na frequência $f_{F}=f_{p}+f_{q}-f_{r}=$ $\omega_{\mathrm{F}} / 2 \pi,(\mathrm{p}, \mathrm{q}, \mathrm{r}=1, \ldots, \mathrm{N} ; \mathrm{p}, \mathrm{q} \neq \mathrm{r}), \mathrm{A}_{\mathrm{s}}(\mathrm{s}=\mathrm{p}, \mathrm{q}, \mathrm{r})$ é $\mathrm{a}$ amplitude de um dos $\mathrm{N}$ canais originalmente lançados na fibra, com frequência $\mathrm{f}$, $\alpha$ é o coeficiente de atenuação da fibra, $\mathrm{n}_{2}$ é o coeficiente de índice de refração não linear, c é a velocidade da luz no vácuo, $A_{\text {eff }}$ é a área efetiva do núcleo da fibra, $\beta_{\mathrm{s}}$ é a constante de fase, ${ }^{*}$ indica complexo conjugado e $\mathrm{i}=\sqrt{-1}$. Assume-se operação em onda contínua CW (continuous wave).

De acordo com a aproximação de bombeio sem depleção, em que as ondas de bombeio são consideradas muito mais intensas que as ondas de FWM geradas, a solução de (1) no final da fibra de comprimento L é escrita como (SOUZA; HARBOE, 2003), (HARBOE; SILVA; SOUZA, 2008a-2008c), (SILVA, 2008):

$$
\begin{aligned}
A_{F}(L)= & i \frac{n_{2} \omega_{F}}{c A_{e f f}} A_{p}(0) A_{q}(0) A_{r}^{*}(0) e^{-\alpha L / 2} \\
& \frac{\exp [(-\alpha+i \Delta \beta) L]-1}{i \Delta \beta-\alpha}
\end{aligned}
$$

onde $\Delta \beta=\beta_{\mathrm{p}}+\beta_{\mathrm{q}}-\beta_{\mathrm{r}}-\beta_{\mathrm{F}}$ representa a diferença das constantes de fase das várias ondas ou, simplesmente, o descasamento de fase.

A potência associada a esta componente de FWM, de frequência $\omega_{\mathrm{F}}=\pi \mathrm{c} / \lambda_{\mathrm{F}}$, é dada por:

$$
\mathrm{P}_{\mathrm{pqr}}(\mathrm{L})=\left|\mathrm{A}_{\mathrm{F}}(\mathrm{L})\right|^{2}=\mathrm{d} \mathrm{P}_{\mathrm{p}}(0) \mathrm{P}_{\mathrm{q}}(0) \mathrm{P}_{\mathrm{r}}(0) \mathrm{G}_{\Delta \beta}
$$

onde $\mathrm{P}_{s}(0)=\left|\mathrm{A}_{\mathrm{s}}(0)\right|^{2}, \mathrm{~s}=\mathrm{p}, \mathrm{q}, \mathrm{r} ; \mathrm{e}$

$$
\mathrm{G}_{\Delta \beta}=\frac{4 \pi^{2} \mathrm{n}_{2}^{2}}{\mathrm{~A}_{\mathrm{eff}}^{2} \lambda_{\mathrm{F}}^{2}} \mathrm{e}^{-\alpha \mathrm{L}}\left|\frac{\exp [(-\alpha+\mathrm{i} \Delta \beta) \mathrm{L}]-1}{\mathrm{i} \Delta \beta-\alpha}\right|^{2}
$$


$\mathrm{Na}$ equação (3), d é chamado de fator de degeneração $(d=1$ se $\mathrm{p}=\mathrm{q} \neq \mathrm{r}$ e d $=2$ se $\mathrm{p} \neq \mathrm{q}$ $\neq \mathrm{r}$ ). $\mathrm{O}$ fator $\mathrm{G}_{\Delta \beta}$ agrega, além das características da fibra óptica, toda a informação relativa ao descasamento de fase entre os sinais p, q e r. Quanto menor o valor de $G_{\Delta \beta}$, menor a potência de FWM gerada. $\mathrm{O}$ valor máximo de $\mathrm{G}_{\Delta \beta}$ ocorre quando $\Delta \beta=0$, ou seja, quando há casamento de fase entre os sinais p, q e $r$.

Uma expressão analítica para o descasamento de fase $\Delta \beta$ é obtida a partir da expansão da constante de fase $\beta$ em série de Taylor em torno de uma dada frequência $f_{0}=c / \lambda_{0}$, que pode ser a frequência de um dos canais, a frequência do zero de dispersão da fibra ou qualquer outra frequência conveniente, e depende da curva do parâmetro de dispersão $\mathrm{D}$ e de sua inclinação (slope), $\mathrm{dD} / \mathrm{d} \lambda$. Em outras palavras, o descasamento de fase depende do tipo de fibra utilizado e do espaçamento entre canais. A condição de casamento de fase $(\Delta \beta=0)$ é praticamente satisfeita em torno de $\lambda_{\mathrm{ZD}}$.

Neste trabalho, são considerados apenas sistemas baseados em fibra DSF, cujas características de dispersão são especificadas na recomendação ITU-T G.653. Com base nesta recomendação, a variação do parâmetro de dispersão $\mathrm{D}$ com o comprimento de onda é descrita como:

$\mathrm{D}=\mathrm{S}\left(\lambda-\lambda_{0}\right)+\mathrm{D}_{0}$

onde $\lambda$ é o comprimento de onda. Os valores de $\mathrm{S}, \lambda_{0}$ e $\mathrm{D}_{0}$, listados na Tabela I, são tomados como as médias dos respectivos valores máximo e mínimo especificados na citada recomendação.

Tabela I - Parâmetros da curva de dispersão de uma fibra DSF

\begin{tabular}{|c|c|c|c|}
\hline$\lambda(\mathrm{nm})$ & $\begin{array}{c}\mathrm{S} \\
\mathrm{ps} / \\
\left.\mathrm{km} . \mathrm{nm}^{2}\right)\end{array}$ & $\lambda_{0}(\mathrm{~nm})$ & $\begin{array}{c}\mathrm{D}_{0}(\mathrm{ps} / \\
\mathrm{km} . \mathrm{nm})\end{array}$ \\
\hline $\begin{array}{c}1460- \\
1525\end{array}$ & $9,587 / 150$ & 1516,139 & $-1,75$ \\
\hline $\begin{array}{c}1525- \\
1575\end{array}$ & $7 / 150$ & 1550,0 & 0 \\
\hline $\begin{array}{c}1575- \\
1625\end{array}$ & $9,785 / 150$ & 1583,861 & 1,75 \\
\hline
\end{tabular}

Os valores dos outros parâmetros que caracterizam a fibra DSF são: coeficiente de atenuação: 0,2 dB/km; diâmetro modal: $8,0 \mu \mathrm{m}$; coeficiente de índice de refração não linear: $2,0 \times 10^{-20} \mathrm{~m}^{2} / \mathrm{W}$.
Esta formulação básica é, então, adaptada a um sistema digital com modulação em amplitude e detecção direta, segundo o modelo descrito em (INOUE, 1994). Neste modelo, os bits 1 e 0 têm igual probabilidade de ocorrência e o receptor é constituído por um fotodiodo avalanche (APD). $\mathrm{O}$ fator $\mathrm{Q}$ do $\mathrm{j}$-ésimo canal $(1 \leq \mathrm{j} \leq \mathrm{N})$ é calculado como (INOUE, 1994):

$$
\begin{aligned}
& \mathrm{Q}_{\mathrm{j}}=\frac{\mathrm{KP}_{\mathrm{j}}}{\sqrt{2 \mathrm{~K}^{2} \mathrm{P}_{\mathrm{j}}^{2} \mathrm{C}_{\mathrm{FWM}}+\mathrm{N}_{\text {th }}+\mathrm{kKP}_{\mathrm{j}}}+\sqrt{\mathrm{N}_{\text {th }}}} \\
& \text { com } \mathrm{N}_{\text {th }}=\frac{\mathrm{Q}_{\mathrm{j} 0}^{2}}{4}\left(\frac{\mathrm{KP}_{\mathrm{j} 0}}{\mathrm{Q}_{\mathrm{j} 0}^{2}}-\mathrm{k}\right)^{2} \\
& \mathrm{C}_{\mathrm{FWM}}=\frac{1}{8} \sum_{\mathrm{p} \neq \mathrm{q} \neq \mathrm{r} \neq \mathrm{s}} \frac{\mathrm{P}_{\mathrm{pqr}}}{\mathrm{P}_{\mathrm{j}}}+ \\
& \frac{1}{4} \sum_{\mathrm{p} \neq \mathrm{q} \neq \mathrm{r}=\mathrm{s}} \frac{\mathrm{P}_{\mathrm{pqr}}}{\mathrm{P}_{\mathrm{j}}}+\frac{1}{4} \sum_{\mathrm{p}=\mathrm{q} \neq \mathrm{r}} \frac{\mathrm{P}_{\mathrm{pqr}}}{\mathrm{P}_{\mathrm{j}}}
\end{aligned}
$$

onde $\mathrm{K}$ é a responsividade do fotodiodo, $\mathrm{P}_{\mathrm{j}}$ é a potência de pico de sinal recebida para o j-ésimo canal (para o bit $0, \mathrm{P}_{\mathrm{j}}=0$ ), $\mathrm{kKP}_{\mathrm{j}}$ é a potência média de ruído de disparo no receptor; $\mathrm{k}=2 \mathrm{~B}_{\mathrm{F}} \mathrm{M}^{\mathrm{Y}}$, sendo $\mathrm{B}_{\mathrm{F}}$ a largura de banda do filtro elétrico, $\mathrm{M}$ e $\mathrm{Y}$ são os fatores multiplicativo de corrente e de excesso de ruído do APD, respectivamente; $\mathrm{N}_{\text {th }}$ é a potência média de ruído térmico no receptor e $\mathrm{C}_{\mathrm{FWM}}$, a razão entre a potência média de FWM e a potência recebida para o bit 1 . No cálculo desta razão, são levados em conta todos os produtos FWM que ocorrem na largura de banda do filtro óptico. $\mathrm{Na}$ equação (6.2), $\mathrm{Q}_{j 0}$ e $\mathrm{P}_{\mathrm{j} 0}$ são os valores do fator $\mathrm{Q}$ e da potência de pico de sinal recebido na ausência de FWM $\left(\mathrm{C}_{\mathrm{FWM}}=0\right)$, respectivamente. Neste trabalho, o limite de validade da aproximação de bombeio sem depleção é arbitrariamente fixado em $\mathrm{C}_{\mathrm{FWM}}=-5 \mathrm{~dB}$ e, assim como em (INOUE, 2004), a contribuição da potência de FWM ao ruído de disparo no receptor é desprezada.

A taxa de erro de bits (BER) do j-ésimo canal $(1 \leq j \leq N)$ é calculada como (INOUE, 1994):

$$
\operatorname{BER}=\frac{1}{2} \operatorname{erfc}\left(\frac{Q_{j}}{\sqrt{2}}\right)
$$

onde erfc designa a função erro complementar. Considera-se que uma BER melhor ou igual a $10^{-12}$ deve ser mantida para cada canal. Para tal, 
os valores da sensibilidade do receptor usados nos cálculos, para as taxas de bits de 2,5 e $10 \mathrm{~Gb} / \mathrm{s}$ são, respectivamente: $-33,5 \mathrm{e}-27 \mathrm{dBm}$.

As equações (1)-(7) fornecem o formalismo matemático necessário para a investigação do mecanismo de FWM em sistemas WDM baseados em fibra DSF e são utilizadas na análise de casos apresentada na Seção 3. Antes, no entanto, uma descrição dos esquemas de alocação de canais é apresentada.

\subsection{ESQUEMAS DE ALOCAÇÃO DE CANAIS}

Em sistemas WDM com espaçamento uniforme entre canais, todos os produtos FWM que ocorrem na largura de banda do sistema coincidem com frequências de canais, resultando em interferência (crosstalk). Para aliviar as limitações impostas pelo mecanismo de FWM, diversas técnicas de alocação de canais com espaçamentos não uniformes têm sido propostas na literatura (KOJIMA; NUMAI, 2006), (NAGATANI, 2008), (ONISHI; KOJIMA; NUMAI, 2007). Embora algumas destas técnicas evitem, de fato, que produtos FWM coincidam em frequência com canais, nenhuma impede a ocorrência dos mesmos na largura de banda do filtro que seleciona o canal. Resultados na literatura (CIARAMELLA, 2002), (KOJIMA; HINO; NUMAI, 2007), (LYUBOMIRSKY, 2002), indicam que esta deve ser especificada de modo judicioso. Para as grades DWDM de 25, 12,5 e $6,25 \mathrm{GHz}$, as correspondentes larguras de banda do filtro óptico empregadas neste trabalho são: 16,8 e $4 \mathrm{GHz}$.

Para todos os esquemas de alocação adotados, o canal central é tomado como o canal de ordem $M=N / 2$, se $N$ for par, ou $M=(N+1) / 2$, se $\mathrm{N}$ for impar, com $\mathrm{N} \geq 3$. Este canal é sempre posicionado na frequência de referência especificada na recomendação ITU-T G694.1: $f_{M}=193,1$ THz. Para conversão entre frequência e comprimento de onda, o valor usado para a velocidade da luz é c $=2,99792458 \times 10^{8} \mathrm{~m} / \mathrm{s}$, de modo que $\lambda_{\mathrm{M}}=1552,524 \mathrm{~nm}$. O canal central encontra-se, portanto, próximo ao zero de dispersão da fibra, que ocorre em $\lambda_{\mathrm{ZD}}=1550 \mathrm{~nm}$.

\section{Espaçamento uniforme (EU)}

No esquema EU, a separação de frequências entre canais adjacentes $(\Delta \mathrm{f})$ é constante, como ilustrado na Figura 1.a; a largura de banda óptica $\left(\mathrm{B}_{\mathrm{EU}}\right)$ para um sistema de $\mathrm{N}$ canais é dada por: $\mathrm{B}_{\mathrm{EU}}$ $=(\mathrm{N}-1) \Delta \mathrm{f}$ e mantida como referência para todos os demais esquemas.

As frequências dos canais são dadas por:

$$
\begin{aligned}
& \mathrm{f}_{\mathrm{M}-\mathrm{i}}=\mathrm{f}_{\mathrm{M}-(\mathrm{i}-1)}-\Delta \mathrm{f}, 1 \leq \mathrm{i} \leq \mathrm{M}-1 \\
& \mathrm{f}_{\mathrm{M}+\mathrm{i}}=\mathrm{f}_{\mathrm{M}+(\mathrm{i}-1)}+\Delta \mathrm{f}, 1 \leq \mathrm{i} \leq \mathrm{N}-\mathrm{M}
\end{aligned}
$$

\section{Espaçamento não uniforme (ENU)}

No esquema ENU, a separação de frequências entre canais adjacentes é crescente $(\mathrm{A}, \mathrm{A}+\mathrm{X}$, $A+2 X, \ldots)$, a partir do primeiro canal até o canal central (de ordem M). Se este esquema fosse mantido até o último canal, como usualmente proposto na literatura (CIARAMELLA, 2002), (KOJIMA; HINO; NUMAI, 2007), (LYUBOMIRSKY, 2002), o maior espaçamento ocorreria entre os canais de ordens $\mathrm{N}-1$ e N. O esquema é, então invertido e, a partir do canal central, é aplicado um espaçamento decrescente, com o maior espaçamento ocorrendo entre os canais de ordens $M$ e $\mathrm{M}+1$. $\mathrm{O}$ esquema é ilustrado na Figura 1.b. $\mathrm{O}$ procedimento adotado visa à redução dos efeitos de FWM nos canais centrais, que estão mais próximos do zero de dispersão da fibra (e, portanto, mais vulneráveis ao efeito de FWM). O incremento X é calculado como:

$X=\left[B_{E U}-(N-1) A\right] \cdot\left(\left(\begin{array}{c}N-2 \\ \sum_{i=1} i\end{array}\right)^{-1}\right.$

As frequências dos canais são dadas por:

$$
\begin{gathered}
\mathrm{f}_{\mathrm{M}-\mathrm{i}}=\mathrm{f}_{\mathrm{M}-(\mathrm{i}-1)}-\{\mathrm{A}+[\mathrm{M}-(\mathrm{i}+1)] \mathrm{X}\} \\
1 \leq \mathrm{i} \leq \mathrm{M}-1 \\
\mathrm{f}_{\mathrm{M}+\mathrm{i}}=\mathrm{f}_{\mathrm{M}+(\mathrm{i}-1)}+\{\mathrm{A}+[\mathrm{N}-(\mathrm{i}+1)] \mathrm{X}\} \\
1 \leq \mathrm{i} \leq \mathrm{N}-\mathrm{M}
\end{gathered}
$$

O esquema ENU se aplica a $\mathrm{N} \geq 3$.

\section{Espaçamento não uniforme repetido (ENUR)} No esquema ENUR (CIARAMELLA, 2002), (KOJIMA; HINO; NUMAI, 2007), (LYUBOMIRSKY, 2002), é utilizada uma grade ENU de quatro canais com espaçamentos (A, $A+X$ e $A+2 X)$, que é repetida periodicamente. $A$ 
alocação de canais é iniciada a partir do canal central, de modo que o maior espaçamento $(A+2 X)$ ocorra entre os canais de ordens $\mathrm{M}$ e $\mathrm{M}+1$, pelo motivo explicado anteriormente. Este esquema é ilustrado na Figura 1.c. O incremento X é calculado como:

$$
X=\left[B_{E U}-(N-1) A\right] \cdot(3 K+L)^{-1}
$$

Para N par,

$\mathrm{K}=\operatorname{Int}[(\mathrm{N}-1) / 3]$, Int $(\cdot)$ representa a parte inteira de $(\cdot)$

$\mathrm{L}=[(\mathrm{N}-1)-3 \mathrm{~K}]\{7-3[(\mathrm{~N}-1)-3 \mathrm{~K}]\} / 2$

Para N impar,

$\mathrm{K}=\operatorname{Int}(\mathrm{N} / 3)$ e $\mathrm{L}=0$

As frequências dos canais são dadas por:

$$
\begin{array}{r}
\mathrm{f}_{\mathrm{M}-\mathrm{i}}=\mathrm{f}_{\mathrm{M}-(\mathrm{i}-1)}-\mathrm{A}-\{2-[\mathrm{i}-3 \operatorname{Int}(\mathrm{i} / 3)]\} \mathrm{X} \\
1 \leq \mathrm{i} \leq \mathrm{M}-1 \\
\mathrm{f}_{\mathrm{M}+\mathrm{i}}=\mathrm{f}_{\mathrm{M+(i-1)}}+\mathrm{A}+[\mathrm{J}(5-3 \mathrm{~J})+1] \mathrm{X} / 2 \\
\mathrm{~J}=\mathrm{i}-3 \operatorname{Int}(\mathrm{i} / 3) \mathrm{e} 1 \leq \mathrm{i} \leq \mathrm{N}-\mathrm{M}
\end{array}
$$

O esquema ENUR se aplica a $\mathrm{N} \geq 4$.

\section{Espaçamento não uniforme refletido (ENU-2)}

No esquema ENU-2, o mesmo espaçamento crescente do esquema ENU é aplicado aos canais de ordens 1 a M. Este esquema é então refletido e aplicado aos canais de ordens $\mathrm{M}+1$ a $\mathrm{N}$, que têm, portanto, espaçamentos decrescentes. Mais uma vez, o maior espaçamento, $[\mathrm{A}+(\mathrm{M}-1) \mathrm{X}]$, é fixado entre os canais de ordens $\mathrm{M}$ e $\mathrm{M}+1$, como indicado na Figura 1.d. O incremento X é calculado como:

$$
X=\left[B_{E U}-(N-1) A\right] \cdot\left[\mathrm{M}-1+2\left(\sum_{\mathrm{i}=1}^{\mathrm{M}-2}\right)\right]^{-1}
$$

Se $M=2$, o valor do somatório é tomado igual a zero. $\mathrm{O}$ esquema ENU-2 se aplica a $\mathrm{N} \geq 3$.

As frequências dos canais são dadas por:

$$
\begin{gathered}
\mathrm{f}_{\mathrm{M}-\mathrm{i}}=\mathrm{f}_{\mathrm{M}-(\mathrm{i}-1)}-\{\mathrm{A}+[\mathrm{M}-(\mathrm{i}+1)] \mathrm{X}\} \\
1 \leq \mathrm{i} \leq \mathrm{M}-1 \\
\mathrm{f}_{\mathrm{M}+\mathrm{i}}=\mathrm{f}_{\mathrm{M}+(\mathrm{i}-1)}+[\mathrm{A}+(\mathrm{M}-\mathrm{i}) \mathrm{X}] \\
1 \leq \mathrm{i} \leq \mathrm{N}-\mathrm{M}
\end{gathered}
$$

\section{Duplo espaçamento uniforme (EU-EU)}

No esquema EU-EU, dois espaçamentos uniformes distintos - A e E - são utilizados, sendo $\mathrm{A}<\mathrm{E}$. O maior espaçamento (E) é aplicado entre os $\mathrm{m}_{1}$ canais à esquerda e os $\mathrm{m}_{2}$ canais à direita do canal central. Entre todos os outros canais é aplicado o menor espaçamento (A), como ilustrado na Figura 1.e. Os valores de $m_{1}$ e $m_{2}$ devem ser tais que $\mathrm{m}_{1}+\mathrm{m}_{2}<\mathrm{N}$, caso contrário este esquema se reduz ao esquema $\mathrm{EU}$, com $\mathrm{E}=\Delta \mathrm{f}$. Para manter $\mathrm{B}_{\mathrm{EU}}$, os espaçamentos $\mathrm{A}$ e $\mathrm{E}$ não são independentes: para um dado valor de $A$, o espaçamento $E$ é calculado como:

$$
E=\left[B_{E U}-\left(\mathrm{N}-1-m_{1}-m_{2}\right) A\right] \cdot\left(m_{1}+m_{2}\right)^{-1}
$$

As frequências dos canais são dadas por:

$$
\begin{aligned}
& \mathrm{f}_{\mathrm{M}-\mathrm{i}}=\mathrm{f}_{\mathrm{M}-(\mathrm{i}-1)}-\mathrm{E}, 1 \leq \mathrm{i} \leq \mathrm{m}_{1} \\
& \mathrm{f}_{\mathrm{M}+\mathrm{i}}=\mathrm{f}_{\mathrm{M}+(\mathrm{i}-1)}+\mathrm{E}, 1 \leq \mathrm{i} \leq \mathrm{m}_{2} \\
& \mathrm{f}_{\mathrm{M}-\mathrm{i}}=\mathrm{f}_{\mathrm{M}-(\mathrm{i}-1)}-\mathrm{A}, \mathrm{m}_{1}+1 \leq \mathrm{i} \leq \mathrm{M}-1 \\
& \mathrm{f}_{\mathrm{M}+\mathrm{i}}=\mathrm{f}_{\mathrm{M}+(\mathrm{i}-1)}+\mathrm{A}, \mathrm{m}_{2}+1 \leq \mathrm{i} \leq \mathrm{N}-\mathrm{M}
\end{aligned}
$$

Este esquema será, também, referido como EU$\mathrm{EU}: \mathrm{m}_{1}, \mathrm{~m}_{2}$.

\section{Espaçamento randômico (RAND)}

No esquema RAND, um espaçamento aleatório $\mathrm{Y}_{\mathrm{i}}(1 \leq \mathrm{i} \leq \mathrm{N}-1)$ é aplicado entre os canais. Cada espaçamento $Y_{i}$ é calculado como $Y_{i}=|V| Y_{\text {max }}$, onde $\mathrm{V}$ é uma variável aleatória de distribuição uniforme e média nula $(-1 \leq \mathrm{V} \leq 1)$ e $\mathrm{Y}_{\text {max }}$ designa o máximo espaçamento tolerado. Um espaçamento mínimo $Y_{\min }$ também é especificado, de modo que $Y_{\min } \leq Y_{i} \leq Y_{\text {max }}$. Como os espaçamentos $Y_{i}$ são aleatórios, não é possível garantir um valor determinado para a largura de banda do sistema, dada por $\sum Y_{i}(i=1, \ldots, N)$. Para remediar esta dificuldade, os espaçamentos $Y_{\text {min }}$ e $Y_{\text {max }}$ são especificados de modo que $\mathrm{Y}_{\text {min }}+\mathrm{Y}_{\max }=2 \Delta \mathrm{f}$. Com isto, a largura de banda do sistema resulta aproximadamente igual a $\mathrm{B}_{\mathrm{EU}}$.

As frequências dos canais são dadas por:

$$
\begin{aligned}
& \mathrm{f}_{M-i}=\mathrm{f}_{M-(\mathrm{i}-1)}-\mathrm{Y}_{M-\mathrm{i}}, 1 \leq \mathrm{i} \leq \mathrm{M}-1 \\
& \mathrm{f}_{\mathrm{M}+\mathrm{i}}=\mathrm{f}_{\mathrm{M}+(\mathrm{i}-1)}+\mathrm{Y}_{\mathrm{M}+(\mathrm{i}-1)}, 1 \leq \mathrm{i} \leq \mathrm{N}-\mathrm{M}
\end{aligned}
$$




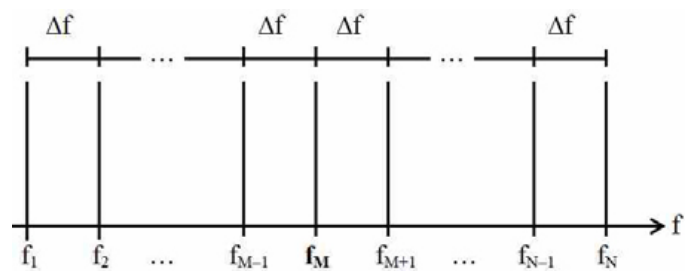

(a)

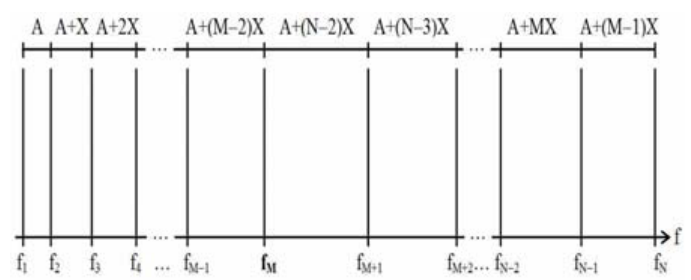

(b)

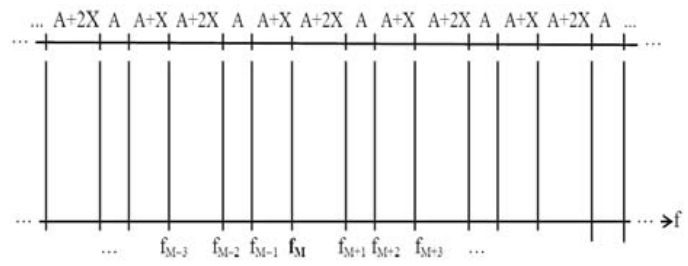

(c)

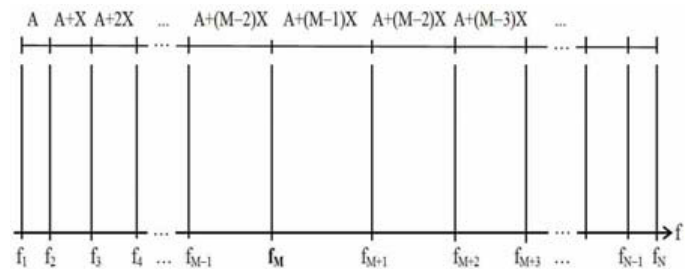

(d)

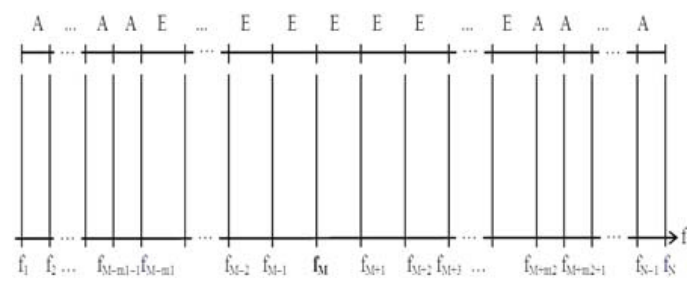

(e)

Figura 1 - Esquemas de alocação de canais na largura de banda do sistema: (a) EU, (b) ENU, (c) ENUR, (d) ENU-2, (e) EU-EU: $\mathrm{m}_{1}, \mathrm{~m}_{2}$

\section{ANÁLISE DE CASOS E DISCUSSÃO DE RESULTADOS}

Este trabalho tem como principal objetivo investigar a influência do posicionamento espectral dos canais na geração de FWM, mantendo constante a largura de banda do sistema, especificada pelo esquema EU. Para isto, diversos esquemas de alocação de canais são propostos e seus desempenhos são comparados.

De uma maneira simples, a realocação de canais é feita variando-se o espaçamento A no inter- valo $1,2 \mathrm{~B}_{\mathrm{OP}}-\Delta$ f. O valor mínimo de $\mathrm{A}\left(1,2 \mathrm{~B}_{\mathrm{OP}}\right)$ foi arbitrariamente fixado, visando garantir que o filtro óptico seleciona um único canal. Em cada esquema de alocação de canais, os outros parâmetros associados são determinados de forma a manter constante a largura de banda $\mathrm{B}_{\mathrm{EU}}$, considerando uma dada grade DWDM. Para os esquemas ENU, ENUR e ENU-2, o incremento X é calculado através de (9), (11.1) e (13), respectivamente; para o esquema EU$\mathrm{EU}: \mathrm{m}_{1}, \mathrm{~m}_{2}$, o espaçamento E é calculado através de (15); para o esquema RAND, os espaçamentos $Y_{\text {min }}$ e $\mathrm{Y}_{\max }$ são escritos, respectivamente, como $\mathrm{Y}_{\min }=\mathrm{A}$ e $\mathrm{Y}_{\max }=(2-\mathrm{A} / \Delta \mathrm{f}) \Delta \mathrm{f}$.

Um exame cuidadoso das Figuras 1.a-e revela que a variação do espaçamento $A$ tem efeitos distintos nos vários esquemas: para os esquemas ENU, ENU-2 e EU-EU, a redução do espaçamento $\mathrm{A}$ corresponde à diminuição do espaçamento entre os canais extremos (mais afastados de $\lambda_{\mathrm{ZD}}$ ) e, consequentemente, ao aumento do espaçamento entre os canais centrais (mais próximos de $\lambda_{\text {ZD }} \mathrm{e}$ mais sensíveis ao efeito de FWM). Para o esquema ENUR, este mesmo comportamento é observado, mas agora considerando a grade de repetição periódica de quatro canais. No caso do esquema RAND, a variação do espaçamento A é distribuída entre todos os canais. É possível, portanto, antecipar que ocorrerão variações da BER entre os canais.

Para um melhor entendimento desses aspectos e avaliação dos esquemas de alocação, várias simulações foram realizadas e os principais resultados, discutidos a seguir, são agrupados em quatro casos.

\section{Caso 1: Potência de entrada e posicionamento de canais}

Inicialmente, consideram-se um sistema de 24 canais, cada qual operando na taxa de transmissão $\mathrm{B}=10 \mathrm{~Gb} / \mathrm{s}$, e a grade $\Delta \mathrm{f}=25 \mathrm{GHz}$. A largura de banda do sistema é, portanto, $\mathrm{B}_{\mathrm{EU}}=575$ $\mathrm{GHz}$. O receptor tem as seguintes características: responsividade: $K=0,8$; fator multiplicativo de corrente: $\mathrm{M}=15$; fator de excesso de ruído: $\mathrm{Y}=$ 0,7 ; sensibilidade de $-27 \mathrm{dBm}$. A largura de banda do filtro elétrico é tomada como igual a $70 \%$ da taxa de transmissão: $\mathrm{B}_{\mathrm{EL}}=7 \mathrm{GHz}$. O comprimento do enlace é $\mathrm{L}=40 \mathrm{~km}$. A análise seguinte se aplica ao canal central $\left(12^{\circ}\right.$ canal). Admite-se, ainda, que todos os canais são lançados na fibra com a mesma potência.

A Figura 2 mostra, para o canal central, a variação da máxima potência de entrada que ga- 
rante uma $\mathrm{BER}=10^{-12}$ em função do espaçamento normalizado percentual $\mathrm{A} / \Delta \mathrm{f}$, considerando os esquemas ENU, ENUR, ENU-2 e RAND. O esquema EU-EU é tratado separadamente, em seguida. $\mathrm{O}$ espaçamento $\mathrm{A}$ é variado no intervalo $1,2 \mathrm{~B}_{\mathrm{OP}}<\mathrm{A}<\Delta \mathrm{f}$, o que corresponde a $77 \%<\mathrm{A} / \Delta \mathrm{f}$ $<100 \%$. O esquema EU, ao qual não se aplica a variação de $\mathrm{A}$, é tomado como referência.

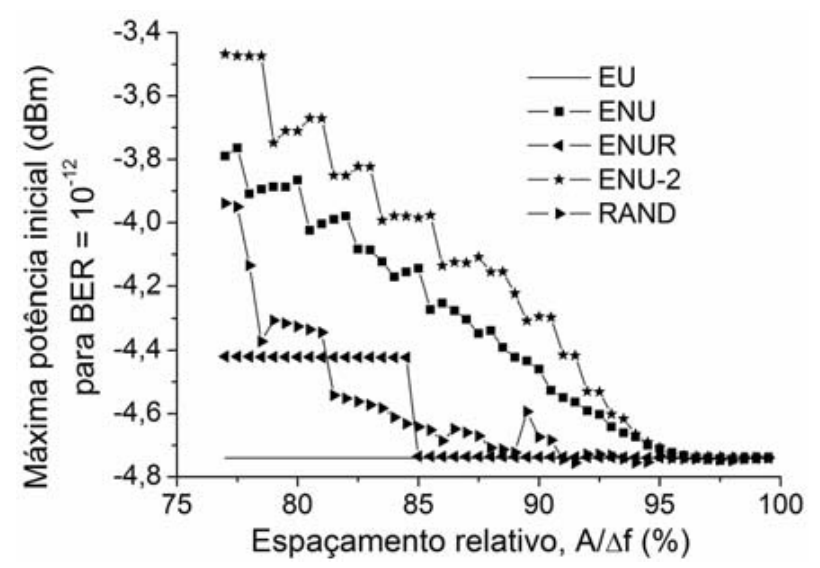

Figura 2 - Variação da máxima potência de entrada para BER $=10^{-12} \mathrm{em}$ função do espaçamento normalizado percentual $\mathrm{A} / \Delta \mathrm{f}$, considerando esquemas de alocação não uniforme, para o $12^{\circ}$ canal de um sistema de 24 canais, $\mathrm{B}=10 \mathrm{~Gb} / \mathrm{s}$ por canal, $\Delta \mathrm{f}=25 \mathrm{GHz}$ e $\mathrm{L}=40 \mathrm{~km}$

Observa-se na Figura 2 que, para todos os esquemas considerados, é possível um aumento da potência de entrada, em comparação com o esquema $\mathrm{EU}$, tão maior quanto menor a razão $\mathrm{A} / \Delta \mathrm{f}$. Este fato é justificado pela redução das penalidades impostas pelo mecanismo de FWM nos canais centrais, como explicado anteriormente. As oscilações observadas nas curvas estão associadas ao comportamento do parâmetro $\Delta \beta$ (por conseguinte, da potência de FWM), e independem do número de canais. A exigência de manter constante a largura de banda do sistema reduz a eficácia dos esquemas ENU e ENUR, em comparação com resultados obtidos sem esta limitação (KOJIMA; NUMAI, 2006), (NAGATANI, 2008), (ONISHI; KOJIMA; NUMAI, 2007). O novo esquema não uniforme proposto (ENU-2), mostrou-se mais eficiente que os demais esquemas e permite um aumento de cerca de $1,2 \mathrm{~dB}$ na potência de entrada do canal $(\operatorname{com} \mathrm{A} / \Delta \mathrm{f}=$ $78 \%$ ), em comparação com o esquema EU. É interessante ressaltar que, quando a exigência de largura de banda constante é relaxada, o esquema ENU-2 tem, em relação ao esquema ENU, a vantagem de requerer menor banda passante. Para os esquemas
ENU-2, ENU, RAND e ENUR, $\operatorname{com} \mathrm{A} / \Delta \mathrm{f}=80 \%$, a máxima potência de entrada (para $\mathrm{BER}=10^{-12}$ ) é de aproximada e respectivamente $-3,7 \mathrm{dBm} ;-3,9$ $\mathrm{dBm} ;-4,3 \mathrm{dBm} ;-4,4 \mathrm{dBm}$. Com o esquema $\mathrm{EU}$, o correspondente valor é $-4,75 \mathrm{dBm}$.

A seguir, o esquema EU-EU é tratado de maneira semelhante, mas separadamente, para que a influência dos parâmetros $\mathrm{m}_{1} \mathrm{e} \mathrm{m}_{2}$, que controlam o número de canais aos quais é aplicado o maior espaçamento E, seja investigada. As características do sistema de 24 canais anteriormente descrito são mantidas.

A Figura 3 mostra, para o canal central, a variação da máxima potência de entrada que garante uma $B E R=10^{-12}$ em função do espaçamento normalizado percentual $\mathrm{A} / \Delta \mathrm{f}$, considerando o esquema EU-EU e diferentes valores dos parâme$\operatorname{tros} m_{1}$ e $m_{2}$. De maneira semelhante à Figura 2, $\mathrm{o}$ aumento da potência de entrada, em comparação com o esquema EU, é tão maior quanto menor a razão $\mathrm{A} / \Delta \mathrm{f}$. Observa-se, também, que as maiores variações de potência ocorrem para $\mathrm{m}_{1}=2$ e $\mathrm{m}_{2}=2$, doravante denominado par $(2,2)$. Estas variações são menos acentuadas à medida que os valores de $\mathrm{m}_{1}$ e $\mathrm{m}_{2}$ aumentam, como por exemplo, para os pares 6,7 e 7,8 . Os pares $(1,1)$ e $(3,4)$ também foram testados, mas as correspondentes curvas não estão mostradas, para melhor visualização e entendimento da Figura 3. Para os pares $(2,2) ;(5,6)$; $(6,7) ;(7,8), \operatorname{com} \mathrm{A} / \Delta \mathrm{f}=80 \%$, a máxima potência de entrada é de aproximada e respectivamente: $-1,2 \mathrm{dBm} ;-3,1 \mathrm{dBm} ;-3,5 \mathrm{dBm} ;-4,4 \mathrm{dBm}$.

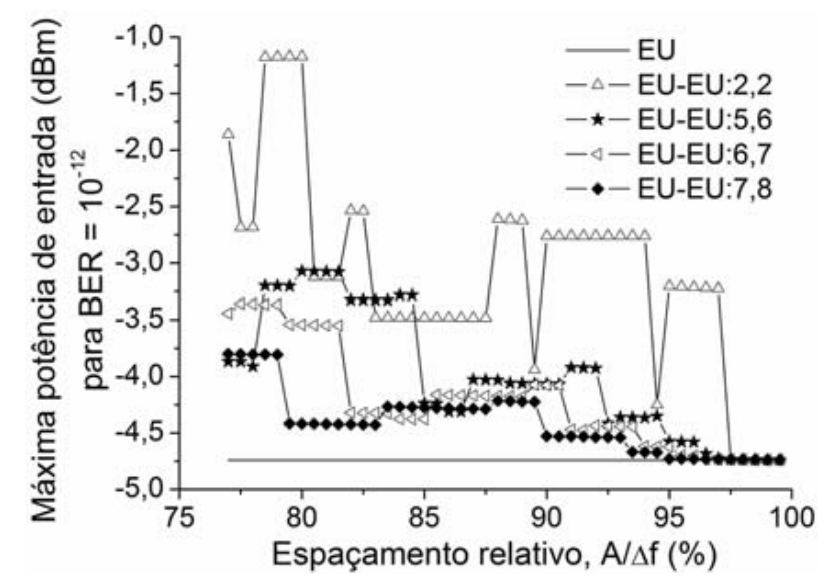

Figura 3 - Variação da máxima potência de entrada para $\mathrm{BER}=10^{-12} \mathrm{em}$ função do espaçamento normalizado percentual $\mathrm{A} / \Delta \mathrm{f}$, considerando o esquema EU-EU e diferentes valores para os parâmetros $\mathrm{m}_{1} \mathrm{e} \mathrm{m}_{2}$, para o $12^{\circ}$ canal de um sistema de 24 canais, $B=10 \mathrm{~Gb} / \mathrm{s}$ por canal, $\Delta \mathrm{f}=25 \mathrm{GHz}$ e L $=40 \mathrm{~km}$ 


\section{Caso 2: BER e avaliação de desempenho}

Neste trabalho, o desempenho dos diversos esquemas de alocação de canais é avaliado pela BER em cada canal [(6) e (7)]. O melhor desempenho se caracteriza pelo maior nível de potência de entrada para todos os canais que assegure uma BER $\leq 10^{-12}$. As simulações realizadas indicaram que, em geral, o esquema EU-EU é o que resulta em maior variação da BER entre os canais, sendo, portanto, objeto da seguinte investigação. Para decidir o par $\left(\mathrm{m}_{1}, \mathrm{~m}_{2}\right) \mathrm{de}$ melhor desempenho, torna-se necessário calcular a BER de todos os canais.

A Tabela II lista, para cada esquema EUEU: $\mathrm{m}_{1}, \mathrm{~m} 2$ anteriormente considerado, os valores calculados para a máxima potência de entrada do canal central $\left(12^{\circ}\right.$ canal $)$ que garante uma BER = $10^{-12}$ e o correspondente espaçamento normalizado $\mathrm{A} / \Delta \mathrm{f}$. Em seguida, os referidos valores foram aplicados aos demais canais para o cálculo da BER associada.

Tabela II - Valores calculados para a máxima potência de entrada do canal central $\left(12^{\circ}\right.$ canal) que garante uma BER $=10^{-12}$ e o correspondente espaçamento normalizado $\mathrm{A} / \Delta \mathrm{f}$, considerando os esquemas EU-EU: $\mathrm{m}_{1}, \mathbf{m}_{2}$ (Sistema de 24 canais, B = $10 \mathrm{~Gb} / \mathrm{s}$ por canal, $\Delta \mathrm{f}=25 \mathrm{GHz}$ e $\mathrm{L}=40 \mathrm{~km}$ )

\begin{tabular}{|c|c|c|}
\hline $\begin{array}{c}\text { Esquema } \\
\text { EU-EU } \\
\mathrm{m}_{1}, \mathrm{~m}_{2}\end{array}$ & $\begin{array}{c}\text { Máxima potência de } \\
\text { entrada (dBm) BER } \\
=10^{-12}\end{array}$ & $\begin{array}{c}\mathrm{A} / \Delta \mathrm{f} \\
(\%)\end{array}$ \\
\hline 1,1 & $-2,19$ & 81 \\
\hline 2,2 & $-1,17$ & 80 \\
\hline 3,4 & $-3,14$ & 81 \\
\hline 5,6 & $-3,07$ & 80 \\
\hline 6,7 & $-3,44$ & 77 \\
\hline 7,8 & $-3,80$ & 78 \\
\hline
\end{tabular}

Embora os esquemas listados na Tabela II garantam uma BER de $10^{-12}$ para o $12^{\circ}$ canal, os cálculos mostraram que apenas os pares 6,7 e 7,8 garantiam BER $\leq 10^{-12}$ para todos os canais e que, com o par $(5,6)$, apenas para o $18^{\circ}$ canal a BER desejada não era obtida. Para este particular esquema e considerando o $18^{\circ}$ canal, a máxima potência de entrada para $B E R=10^{-12}$, com $A / \Delta f=80 \%$ foi calculada como $-3,09 \mathrm{dBm}$. Este valor é maior que os permitidos com os pares 6,7 e 7,8, segundo a Tabela II. Conclui-se, portanto, que o esquema EUEU:5,6 apresenta o melhor desempenho dentre os pares $\mathrm{m}_{1}, \mathrm{~m}_{2}$ estudados, e é então comparado ao dos outros esquemas de alocação de canais considerados nas simulações que prosseguem.

A Figura 4 mostra a BER por canal para os diversos esquemas de alocação de canais, considerando uma potência de entrada por canal de $-4,75$ $\mathrm{dBm}$, que, com o espaçamento uniforme EU, é a máxima potência que garante $\mathrm{BER} \leq 10^{-12}$ para todos os canais. Como esperado, os canais vizinhos ao canal central são mais penalizados pelo efeito de FWM (menor descasamento de fase) e, portanto, experimentam pior BER, quando comparados com os canais extremos. De um modo geral, no entanto, para todos os esquemas de alocação de canais, são observadas melhoras significativas na BER do sistema, quando comparadas ao esquema EU.

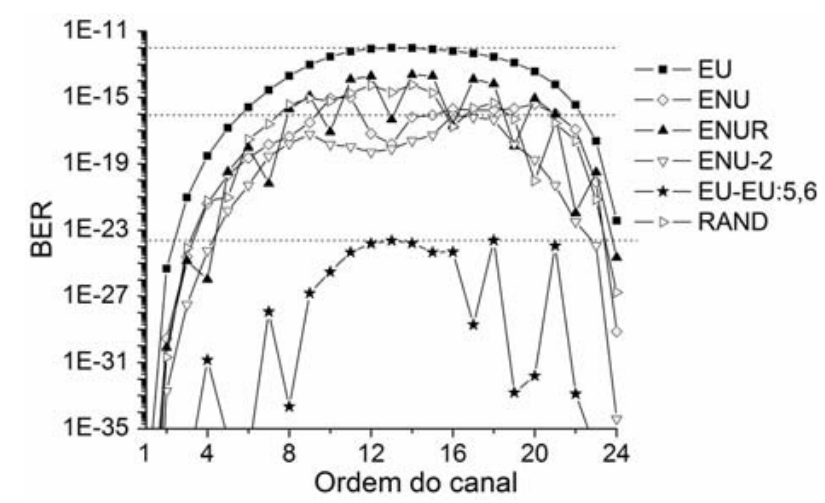

Figura 4 - BER por canal para os diversos esquemas de alocação de canais, com $\mathrm{A} / \Delta \mathrm{f}$ $=80 \%$, para um sistema de 24 canais, $B=$ $10 \mathrm{~Gb} / \mathrm{s}$ por canal, $\Delta \mathrm{f}=25 \mathrm{GHz}, \mathrm{L}=40 \mathrm{~km} \mathrm{e}$ $-4,75 \mathrm{dBm}$ de potência de entrada por canal

Por exemplo, o esquema EU-EU:5,6, de melhor desempenho dentre os esquemas investigados, garante uma BER $<10^{-22}$ ou, alternativamente, um aumento de $1,66 \mathrm{~dB}(\mathrm{de}-4,75 \mathrm{dBm}$ para $-3,09 \mathrm{dBm}$ ) na potência de entrada por canal para uma $B E R=10^{-12}$. Este aumento de potência, denominado margem de potência, pode se traduzir em uma correspondente diminuição da sensibilidade do receptor ou em um aumento do comprimento do enlace. Uma outra possibilidade, ainda, é aumentar o espaçamento entre canais (aumento da razão $\mathrm{A} / \Delta \mathrm{f}$ ). $\mathrm{O}$ esquema ENU-2 tem o segundo melhor desempenho e garante uma BER $<10^{-16}$ para todos os canais.

Outros resultados comprovam que, quando o esquema EU-EU:5,6, com $\mathrm{A} / \Delta \mathrm{f}=80 \%$, é usado como referência (ou seja, máxima potência de entrada por canal de $-3,09 \mathrm{dBm}$ ), todos os outros esque- 
mas de alocação de canais têm desempenho inferior: apenas os canais mais afastados do zero de dispersão da fibra, e que experimentam menor dispersão cromática, conseguem manter uma BER $\leq 10^{-12}$.

A comparação de desempenho dos esquemas de alocação de canais é estendida para o caso de um sistema de 48 canais, mantendo-se todas as outras características do sistema de 24 canais já estudado. As muitas simulações realizadas indicaram que o par $(11,12)$, com $A / \Delta f=80 \%$ apresenta o melhor desempenho. Para este sistema, com o esquema $\mathrm{EU}$, a máxima potência de entrada por canal é $-6,82 \mathrm{dBm}\left(\mathrm{BER} \leq 10^{-12}\right)$ para todos os canais, enquanto o esquema EU-EU:11,12 possibilita aumentar esta potência para $-5,42 \mathrm{dBm}$, ou seja, uma margem de potência de 1,4 dB. Sem dúvida, esta margem de potência é tão menor quanto maior o número de canais, uma vez que mais potência de FWM está sendo gerada.

A Figura 5 mostra a BER por canal, com potência de entrada de $-6,82 \mathrm{dBm}$ por canal, para todos os esquemas de alocação de canais, com $\mathrm{A} / \Delta \mathrm{f}=80 \%$, evidenciando o melhor desempenho do esquema EU-EU:11,12 em relação aos demais: este esquema garante BER $<10^{-21}$ para todos os canais. O esquema ENU-2 tem, novamente, o segundo melhor desempenho, garantindo uma BER $<10^{-16}$ para todos os canais.

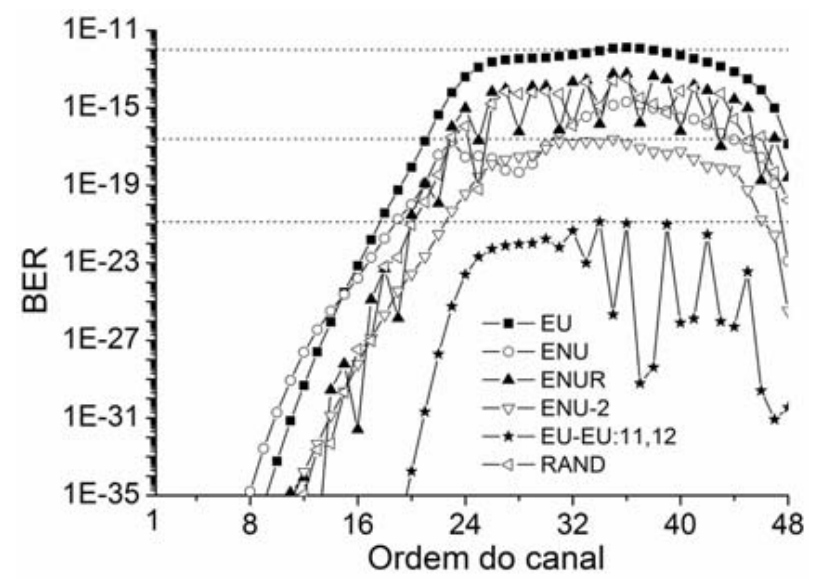

Figura 5 - BER por canal para os diversos esquemas de alocação de canais, com $\mathrm{A} / \Delta \mathrm{f}$ $=80 \%$, para um sistema de 48 canais, $\mathrm{B}=$ $10 \mathrm{~Gb} / \mathrm{s}$ por canal, $\Delta \mathrm{f}=25 \mathrm{GHz}, \mathrm{L}=40 \mathrm{~km} \mathrm{e}$ $-6,82 \mathrm{dBm}$ de potência de entrada por canal

Uma comparação das Figuras 4 e 5 mostra que o comportamento assimétrico das curvas de BER em relação ao canal central é acentuado à medida que o número de canais cresce. Este fato é explicado pelo aumento significativo de produtos FWM na largura de banda do filtro óptico.

Para completar o estudo, as influências do comprimento do enlace e das grades ultrafinas 12,5 e $6,25 \mathrm{GHz}$ - são investigadas.

\section{Caso 3: Potência de entrada e comprimento do} enlace

Em trabalhos anteriores (HARBOE; SILVA; SOUZA, 2008a-2008c), os autores verificaram que o desempenho de sistemas WDM, então avaliado pela relação sinal-ruído (SNR), dependia do comprimento do enlace, do tipo de fibra empregado e da grade DWDM considerada. Isto significa que a BER do sistema também depende desses fatores e que a potência de entrada dos canais deve ser cuidadosamente ajustada.

No presente estudo, são considerados os esquemas EU-EU:5,6 e EU-EU:11,12, que comprovadamente apresentaram melhor desempenho nos casos de sistemas de 24 e 48 canais, respectivamente. $\mathrm{O}$ ambiente de simulação é semelhante aos das Figuras 4 e 5. Em cada caso, foi escolhido o canal com maior BER (pior desempenho): o $18^{\circ}$ para o sistema de 24 canais e o $34^{\circ}$ para o sistema de 48 canais. A Figura 6 mostra a variação da máxima potência de entrada por canal em função do comprimento do enlace para uma BER $=10^{-12}$. $\mathrm{O}$ esquema EU é, mais uma vez, utilizado como referência de comparação de desempenho.

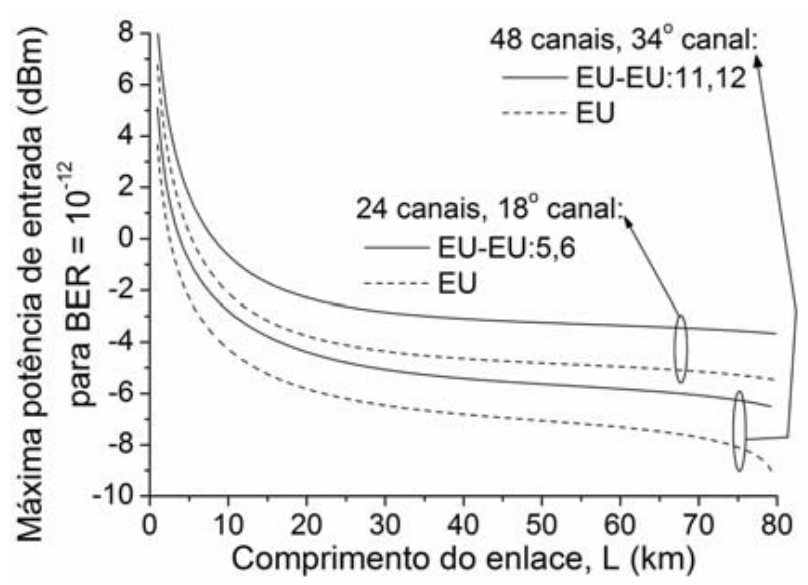

Figura 6 - Variação da máxima potência de entrada para $\mathrm{BER}=10^{-12}$, em função do comprimento do enlace, para sistemas de $24 \mathrm{e}$ 48 canais, $\mathrm{B}=10 \mathrm{~Gb} / \mathrm{s}$ por canal, $\Delta \mathrm{f}=25 \mathrm{GHz}$, considerando os esquemas de alocação EU e $\mathrm{EU}-\mathrm{EU}(\mathrm{A} / \Delta \mathrm{f}=\mathbf{8 0} \%)$ 
Em fibras DSF, a condição de casamento de fase é praticamente satisfeita e a geração de FWM é significativa. Este fato é aparente na Figura 6, onde os níveis de potência de entrada por canal decaem exponencialmente [de acordo com (4)] para curtos trechos de fibra e independem do esquema considerado. À medida que o comprimento aumenta e ultrapassa um certo valor, observamse poucas variações na potência e a separação entre as curvas dos esquemas EU-EU e EU permanece praticamente constante. No caso de 24 canais, esta condição corresponde a $\mathrm{L}-20 \mathrm{~km}$, enquanto que para 48 canais, L - $30 \mathrm{~km}$. Percebe-se, também, que o desempenho do esquema EU-EU melhora, em comparação ao do esquema EU, à medida que o comprimento da fibra aumenta. No caso de 24 canais, com $80 \mathrm{~km}$ de fibra, o esquema EUEU permite uma potência de entrada cerca de 1,8 $\mathrm{dB}$ maior que a permitida pelo esquema $\mathrm{EU}$ (em comparação à margem de 1,66 dB com $40 \mathrm{~km}$ ). No caso de 48 canais, segundo o modelo de bombeio sem depleção, 79,2 km é o máximo comprimento de fibra para o qual o esquema EU garante uma BER $=10^{-12}$, para o canal considerado na Figura 6. Nesta situação, o esquema EU-EU permite um aumento de cerca de $2,5 \mathrm{~dB}$ na potência de entrada (em comparação à margem de 1,4 dB com $40 \mathrm{~km}$ ). Além disto, com o esquema EUEU: 11,12 considerado, a BER de $10^{-12}$ é garantida com até $86 \mathrm{~km}$.

\section{Caso 4: Grades ultrafinas de 12,5 e $6,25 \mathrm{GHz}$}

Os resultados obtidos até aqui permitem concluir que, de fato, o esquema EU-EU é o que apresenta melhor desempenho. Todavia, a identificação do correspondente par $\left(\mathrm{m}_{1}, \mathrm{~m}_{2}\right)$ é criteriosa, pois depende dos parâmetros do sistema, sendo o número de canais o de maior importância. Outras simulações realizadas revelaram que a grade DWDM e a taxa de transmissão influenciam apenas marginalmente, como sumarizado nos resultados seguintes.

Consideram-se as grades DWDM de espaçamentos ultrafinos 12,5 e $6,25 \mathrm{GHz}$ e sistemas de 24 e 48 canais, com até $80 \mathrm{~km}$ de fibra DSF, operando à taxa de $2,5 \mathrm{~Gb} / \mathrm{s}$ por canal. Além disto, para a grade de $6,25 \mathrm{GHz}$, alguns parâmetros do receptor são ajustados à nova taxa de transmissão: a banda passante do filtro elétrico, que corresponde a $70 \%$ da taxa de transmissão, é reduzida para $\mathrm{B}_{\mathrm{EL}}=1,75 \mathrm{GHz}$; a sensibilidade passa $\mathrm{a}-33,5 \mathrm{~dB}$; os demais parâmetros são mantidos. As simulações foram realizadas de maneira semelhante aos Casos 2 e 3.

Para $\Delta \mathrm{f}=12,5 \mathrm{GHz}$, os resultados correspondentes aos melhores desempenhos são: (i) Sistema de 24 canais: $\operatorname{par}(5,6), 18^{\circ}$ canal, $\mathrm{A} / \Delta \mathrm{f}=81$ $\%$. A margem de potência é de $1,61 \mathrm{~dB}$ (de $-5,87$ $\mathrm{dBm}$, com o esquema $\mathrm{EU}$, para $-4,26 \mathrm{dBm}$ ), com $\mathrm{L}=40 \mathrm{~km}$. Esta margem aumenta muito pouco, para cerca de $1,67 \mathrm{~dB}$, com $\mathrm{L}=80 \mathrm{~km}$. (ii) Sistema de 48 canais: $\operatorname{par}(11,12), 26^{\circ}$ canal, $\mathrm{A} / \Delta \mathrm{f}=80$ $\%$. A margem de potência é de $1,4 \mathrm{~dB}$ (de $-7,88$ $\mathrm{dBm}$, com o esquema $\mathrm{EU}$, para $-6,48 \mathrm{dBm}$ ), com $\mathrm{L}=40 \mathrm{~km}$. Esta margem também aumenta muito pouco, para cerca de $1,5 \mathrm{~dB}$, com $\mathrm{L}=80 \mathrm{~km}$.

Para $\Delta \mathrm{f}=6,25 \mathrm{GHz}$, os resultados correspondentes aos melhores desempenhos são: (i) Sistema de 24 canais: $\operatorname{par}(5,6), 18^{\circ} \mathrm{canal}, \mathrm{A} / \Delta \mathrm{f}=81$ $\%$. A margem de potência é de $1,46 \mathrm{~dB}$ (de $-5,95$ $\mathrm{dBm}$, com o esquema $\mathrm{EU}$, para $-4,49 \mathrm{dBm})$, com $\mathrm{L}=40 \mathrm{~km}$. (ii) Sistema de 48 canais: par $(11,12)$, $39^{\circ}$ canal, $\mathrm{A} / \Delta \mathrm{f}=80 \%$. A margem de potência é de $1,22 \mathrm{~dB}$ (de $-8,72 \mathrm{dBm}$, com o esquema EU, para $-7,51 \mathrm{dBm})$, com $\mathrm{L}=40 \mathrm{~km}$. Mais uma vez, para $\mathrm{L}=80 \mathrm{~km}$, os aumentos de potência são marginais: $1,5 \mathrm{~dB}$ e $1,3 \mathrm{~dB}$ para os sistemas de 24 e 48 canais, respectivamente.

É interessante observar que, para as grades ultrafinas de $12,5 \mathrm{GHz}$ e $6,25 \mathrm{GHz}$, com $\mathrm{B}=2,5$ $\mathrm{Gb} / \mathrm{s}$, o aumento da margem de potência com o comprimento de fibra é menor que o observado no Caso 3 (grade de $25 \mathrm{GHz}, \mathrm{B}=10 \mathrm{~Gb} / \mathrm{s}$ ). Outras simulações mostraram que esta redução está associada à menor taxa de transmissão e não aos menores espaçamentos.

Para completar o estudo, as grades de $100 \mathrm{e}$ $50 \mathrm{GHz}$ também foram exploradas, considerando as taxas de transmissão de 10 e $2,5 \mathrm{~Gb} / \mathrm{s}$. $\mathrm{O}$ ambiente de simulação é idêntico ao das simulações anteriores, exceto pela largura de banda do filtro óptico: $\mathrm{B}_{\text {op }}=56 \mathrm{GHz}$, para $\Delta \mathrm{f}=100 \mathrm{GHz}$, e $\mathrm{B}_{\text {op }}=$ $28 \mathrm{GHz}$, para $\Delta \mathrm{f}=50 \mathrm{GHz}$. De um modo geral, os resultados são previsíveis: o esquema EU-EU é o de melhor desempenho, mas agora acompanhado bem de perto pelo esquema ENUR. Por exemplo, para o sistema de 48 canais, $10 \mathrm{~Gb} / \mathrm{s}, 50 \mathrm{GHz}$, as discrepâncias entre os esquemas EU-EU e ENUR são menores que $0,05 \mathrm{~dB}$. Neste caso, a margem de potência é da ordem de $1,7 \mathrm{~dB}(\mathrm{de}-4,50 \mathrm{dBm}$, com o esquema $\mathrm{EU}$, para $-2,78 \mathrm{dBm}$ ), com $\mathrm{L}=$ $40 \mathrm{~km}$. 


\section{CONCLUSÔES}

Este trabalho investigou a influência do posicionamento espectral de canais em sistemas DWDM baseados em fibras DSF na geração de FWM, mantendo constante a largura de banda do sistema. $\mathrm{O}$ modelo utilizado supóe bombeio sem depleção e permite avaliar o descasamento de fase, potência de FWM e a BER do sistema. $\mathrm{Na}$ análise, foram consideradas as grades DWDM especificadas pela recomendação ITU-T G.694.1 e também a grade ultrafina de $6,25 \mathrm{GHz}$. Os resultados indicam que as penalidades impostas por FWM podem, de fato, ser reduzidas com a realocação dos canais, mantendo a largura de banda do sistema. Dentre os seis esquemas de alocação de canais considerados, o esquema EUEU: $m_{1}, m_{2}$, proposto pelos autores neste trabalho, mostrou-se o mais eficiente, propiciando uma melhora significativa da BER. Contudo, a determinação do par $\left(\mathrm{m}_{1}, \mathrm{~m}_{2}\right)$ que leva ao melhor desempenho exige uma investigação criteriosa. As numerosas simulações indicaram que o par $\left(\mathrm{m}_{1}, \mathrm{~m}_{2}\right)$ é determinado, principalmente, pelo número de canais. A grade DWDM e a taxa de transmissão, por sua vez, afetam o valor ótimo do espaçamento $\mathrm{A}$.

Outras simulações também sugeriram que o desempenho do esquema EU-EU: $\mathrm{m}_{1}, \mathrm{~m}_{2}$ melhora, em relação aos demais, nas grades DWDM com menor espaçamento $\Delta$ f. Por exemplo, nas grades com espaçamentos de 100 e $50 \mathrm{GHz}$, os desempenhos dos esquemas EU-EU:m ${ }_{1}, \mathrm{~m}_{2}$ e ENUR são praticamente equivalentes. Os resultados indicaram, ainda, que, de um modo geral, a margem de potência propiciada pelo esquema EU-EU: $\mathrm{m}_{1}, \mathrm{~m}_{2}$ aumenta com o comprimento do enlace e com a taxa de transmissão.

\section{REFERÊNCIAS}

CIARAMELLA E. Nonlinear Impairments in Extremely Dense WDM Systems, IEEE Photonics Tech. Lett., v. 14, n. 14, p. 804-806, 2002.

HARBOE, P.B., SILVA, E., SOUZA, J.R. Simulador WDM para Análise das Penalidades Impostas por FWM em Fibras G.652, G.653 e G.655, Anais MOMAG 2008: $13^{\mathrm{O}}$ SBMO Simpósio Brasileiro de Microondas e Optoeletrônica e $8^{\circ}$
CBMag Congresso Brasileiro de Eletromagnetismo, Florianópolis SC, 2008a.

. FWM em Sistemas DWDM: Espaçamento Não Uniforme versus Espaçamento Uniforme, Anais SBrT’08: XXVI Simpósio Brasileiro de Telecomunicações, Rio de Janeiro RJ, 2008b.

Analysis of FWM Penalties in DWDM Systems Based on G.652, G.653, and G.655 Optical Fibers, in Proceedings of World Academy of Science, Engineering and Technology, v. 35, Bangkok, Thailand, 2008c.

INOUE K. et al. Crosstalk and Power Penalty Due to Fiber Four-Wave Mixing in Multichannel Transmissions, IEEE J. Lightwave Tech., v. 12, n. 8, p. 1423-1439, 1994.

KOJIMA S., NUMAI T. Theoretical Analysis of Modified Repeated Unequally Spaced Frequency Allocations in FDM Lightwave Transmission Systems, IEEE J. Lightwave Tech., v. 24, n. 7, p. 2786- 2797, 2006.

KOJIMA S., HINO T., NUMAI T. Influence of Frequency Allocations and Optical Filters on FDM Optical Fiber Communications, IEEE J. Lightwave Tech., v. 25, n. 12, p. 3694-3703, 2007.

LAWSON J. Projeto Distributed.net, http://www. distributed.net, visitado em 21/09/2009.

LYUBOMIRSKY I. et al. Optimum 10-Gb/s NRZ Receiver Bandwidths for Ultradense WDM Transmission Systems, IEEE Photonics Tech. Lett., v. 14 , n. 6 , p. 870-872, 2002.

MIZUNO, T. et al. 12.5-GHz Spacing Compact and Low-Loss Interleave Filter Using 1.5\% Silica-Based Waveguide, IEEE Photonics Tech. Lett., v. 16, n. 11, p. 2484-2486, 2004.

NAGATANI Y. et al. Theoretical Analysis of Frequency Allocations in FDM Lightwave Transmission Systems, IEEE J. Lightwave Tech., v. 26, n. 13, p. 1993-2001, 2008.

OHARA, T. et al. $1000 \times 2.67 \mathrm{~Gb} / \mathrm{s}$ ultra-dense WDM transmission using supercontinuum multi-carrier source, IEIC Technical Report (In- 
stitute of Electronics, Information and Communication Engineers), v. 105, n. 32, OCS2005-7, p. 23-28, 2005.

ONISHI J. et al. Effects of Frequency Allocations and Zero-Dispersion Frequencies on FDM Lightwave Transmission Systems, IEEE J. Lightwave Tech., v. 25, n. 7, p. 1719-1727, 2007.

SILVA, E. Simulador WDM para Análise das Penalidades Impostas por Mistura de Quatro Ondas (FWM) em Fibras Ópticas Monomodo SMF,
DSF e NZDSF. Dissertação de Mestrado apresentada ao Departamento de Engenharia de Telecomunicações da Universidade Federal Fluminense, Niterói, 2008.

SOUZA, J.R., HARBOE, P.B. Assessment of Higher-Order Exponential Operators for the Simulation of High-Capacity Optical Communication Systems by the Split-Step Fourier Method, J. of Microwaves and Optoelectronics, v. 3, n. 2, p. 9-22, 2003. 